\title{
Short communication: Supply of methionine during late pregnancy enhances whole-blood innate immune response of Holstein calves partly through changes in mRNA abundance in polymorphonuclear leukocytes
}

\author{
A. S. Alharthi, ${ }^{1,2}$ V. Lopreiato, ${ }^{3}$ H. Dai, ${ }^{4}$ R. Bucktrout, ${ }^{1}$ M. Abdelmegeid, ${ }^{5}$ F. Batistel, ${ }^{6}$ C. Parys,${ }^{7}$ X. Shen, ${ }^{4}$ \\ M. A. Ballou, ${ }^{8}$ E. Trevisi, ${ }^{3}$ I. A. Alhidary, ${ }^{2}$ M. M. Abdelrahman, ${ }^{2}$ and J. J. Loor ${ }^{1 *}$ \\ ${ }^{1}$ Mammalian NutriPhysioGenomics, Department of Animal Sciences and Division of Nutritional Sciences, University of Illinois, Urbana 61801 \\ ${ }^{2}$ Department of Animal Production, College of Food and Agriculture Sciences, King Saud University, Riyadh 11451, Saudi Arabia \\ ${ }^{3}$ Department of Animal Sciences, Food and Nutrition, Università Cattolica del Sacro Cuore, Piacenza 29122, Italy \\ ${ }^{4}$ Department of Clinical Veterinary Medicine, Nanjing Agricultural University, Nanjing 210095, PR China \\ ${ }^{5}$ Department of Animal Medicine, Faculty of Veterinary Medicine, Kafrelsheikh University, Kafr El-Shaikh 33516, Egypt \\ ${ }^{6}$ Department of Animal, Dairy and Veterinary Sciences, Utah State University, Logan 84322 \\ ${ }^{7}$ Evonik Nutrition and Care GmbH, 63457 Hanau-Wolfgang, Germany \\ ${ }^{8}$ Department of Animal Sciences, Texas Tech University, Lubbock 79409
}

\section{ABSTRACT}

The supply of methionine (Met) in late pregnancy can alter mRNA abundance of genes associated with metabolism and immune response in liver and polymorphonuclear leukocytes (PMN) of the neonatal calf. Whether prenatal supply of Met elicits postnatal effects on systemic inflammation and innate immune response of the calf is not well known. We investigated whether enhancing the maternal supply of Met via feeding ethyl-cellulose rumen-protected Met (RPM) was associated with differences in calf innate immune response, mRNA abundance in PMN, and systemic indicators of inflammation during the first $50 \mathrm{~d}$ of life. Calves ( $\mathrm{n}=14$ per maternal diet) born to cows fed RPM at $0.09 \%$ of diet dry matter per day (MET) for the last $28 \pm 2 \mathrm{~d}$ before calving or fed a control diet with no added Met (CON) were used. Blood for biomarker analysis and isolation of PMN for innate immune function assays and mRNA abundance was harvested at birth (before colostrum feeding) and at 7 , 21 , and $50 \mathrm{~d}$ of age. Whole blood was challenged with enteropathogenic bacteria (Escherichia coli 0118:H8), and phagocytosis and oxidative burst of neutrophils and monocytes were quantified via flow cytometry. Although concentration of haptoglobin and activity of myeloperoxidase among calves from both maternal groups increased markedly between 0 and $7 \mathrm{~d}$ of age, followed by a decrease to baseline at $\mathrm{d} 21$, the responses were lower in MET compared with CON calves. Nitric

Received September 10, 2018.

Accepted July 2, 2019.

*Corresponding author: jloor@illinois.edu oxide concentration decreased markedly between 0 and 7 $\mathrm{d}$, regardless of maternal group, but MET calves tended to have lower overall concentrations during the study. In vitro phagocytosis in stimulated neutrophils increased markedly over time in both CON and MET calves, but responses were overall greater in MET calves. Oxidative burst in both neutrophils and monocytes increased over time regardless of maternal treatment. The mRNA abundance of lactate dehydrogenase ( $L D H A)$, signal transducer and activator of transcription 3 (STAT3), and S100 calcium binding protein A8 (S100A8) in PMN was overall greater in MET calves. Overall, data suggest that increasing the maternal supply of Met during late pregnancy could affect the neonatal calf inflammatory status and innate immune response. Although changes in mRNA abundance could play a role in coordinating the immune response, the exact mechanisms merit further study

Key words: methyl donor, immune function, nutrition, pregnancy

\section{Short Communication}

The development of the immune system in calves, including PMN functions such as phagocytosis and respiratory burst, is a slow process that requires several months of life to reach a mature state (Kampen et al., 2006). As the primary mediators of the innate immune response, PMN represent the first line of defense against pathogens, and a carefully orchestrated and complex set of signal transduction events leads to their recruitment (Kobayashi and DeLeo, 2009; Futosi et al., 2013). Considering also that passive immunity acquired from colostrum remains active only up to approximately 21 $\mathrm{d}$ of age, the neonatal stage encompasses a wide win- 
dow of susceptibility to stress and immune challenges (Chase et al., 2008; Ranade et al., 2014).

Recent research has focused on how manipulation of maternal nutrition during late pregnancy alters or can improve calf health and reduce stress during neonatal and weaning periods (Osorio et al., 2013b; Jacometo et al., 2016). A nutritional strategy that our group has been researching is to enhance the maternal supply of methionine (Met) by feeding rumen-protected methionine (RPM) during the last 3 to 4 weeks prepartum. Methyl donors serve as precursors of S-adenosylmethionine and are important sources of the antioxidants glutathione (GSH) and taurine, both of which have been associated with decreased oxidative stress and inflammatory status (as judged by plasma biomarkers and liver tissue glutathione; Osorio et al., 2014; Zhou et al., 2017; Batistel et al., 2018).

Tremendous advances have been made over the years in our knowledge of the nutritional physiology of the calf (Blum, 2006). However, the extent to which prenatal maternal nutrition affects the molecular profiles of inflammatory pathways and PMN function in the neonatal animal are not well defined. In an in vitro evaluation of the effect of Met supplementation in neonatal Holstein calf PMN, Abdelmegeid et al. (2017) concluded that an "ideal" supply of Lys relative to Met $(2.9: 1)$ decreased pro-inflammatory signaling and affected the antioxidant systems. These data underscored an important role of Met supply in establishing an adequate immune response during the neonatal period, presumably leading to better immunological status in vivo. The potential role of maternal nutrition on immune adaptations of the neonatal calf likely encompasses key metabolic organs (Li et al., 2015; Du et al., 2018; Zhu et al., 2019). The primary aim of the present study was to generate additional in vivo data related to oxidative burst, phagocytosis capacity, plasma biomarkers, and mRNA abundance related to certain aspects of immune function. To address these objectives, a subset of calves from the entire cohort of animals in the study of Batistel et al. (2017) was used.

The Institutional Animal Care and Use Committee at the University of Illinois Urbana-Champaign (protocol 14270) approved all experimental procedures. Details of the maternal treatments were described previously (Batistel et al., 2017). Briefly, 60 multiparous Holstein cows were fed with a basal control diet (CON; $1.47 \mathrm{Mcal} / \mathrm{kg}$ of DM, $15.6 \% \mathrm{CP}$ ), with no addition of methionine, or the basal diet plus ethyl-cellulose rumen-protected methionine (MET; Mepron, Evonik Nutrition and Care GmbH, Hanau-Wolfgang, Germany) during the last $28 \mathrm{~d}$ of pregnancy. The supplemental methionine was top-dressed on the total mixed diet at a rate of $0.09 \%$ of DM. This supply of Met was based on experiments demonstrating a benefit of achieving a Lys:Met ratio close to 2.8:1 in terms of production performance and health (Osorio et al., 2013a; Zhou et al., 2016).

After parturition, calves were removed from their dams immediately, and cows were milked in the parlor, where the volume of colostrum was recorded and $\operatorname{IgG}$ content estimated at room temperature $\left(22^{\circ} \mathrm{C}\right)$ based on specific gravity, with a bovine colostrometer (Nasco, Fort Atkinson, WI; catalog number C10978N). As in previous studies (McGuirk and Collins, 2004), only calves with maternal colostrum containing at least 50 $\mathrm{mg} / \mathrm{dL}$ of IgG were used in the study. Calves were fed $3.8 \mathrm{~L}$ of fresh colostrum from their respective dams using nipple bottles within $6 \mathrm{~h}$ after birth. If the dam produced less than $3.8 \mathrm{~L}$, the calves were removed from the study.

Details of animal housing and milk replacer were described previously (Xu et al., 2018). Briefly, calves were housed in individual outdoor hutches and fed twice daily with a milk replacer (Advance Excelerate, Milk Specialties, Carpentersville, IL; $28.5 \%$ CP, $15 \%$ fat) until $35 \mathrm{~d}$ of age. At this point they were switched to once-daily feeding until weaning (42 d of age). From d 1 until 56 d of life, calves had ad libitum access to a starter grain mix (Ampli-Calf STR 20 R50, Purina, St. Louis, MO; minimum $19.9 \%$ CP, maximum $13.5 \%$ NDF, maximum $9.0 \%$ ADF).

Blood samples were collected from the jugular vein (n $=14$ calves per group) at birth and at 7, 21, 42, and 50 $\mathrm{d}$ of age and used for blood biomarkers (Table 1), PMN isolation, and measurement of phagocytosis capacity and oxidative burst activity. The vacutainer tubes used contained lithium heparin, and plasma was obtained by centrifugation at $1,900 \times g$ for $15 \mathrm{~min}$ at $4^{\circ} \mathrm{C}$ and stored at $-80^{\circ} \mathrm{C}$ until further analysis. Aspartate aminotransferase (AST, catalog number 0018257540), bilirubin (catalog number 0018254640), gamma-glutamyl transferase (GGT, catalog number 0018254240), and haptoglobin in plasma were measured with kits purchased from Instrumentation Laboratory SpA (Werfen Co., Milan, Italy) using a clinical auto-analyzer (ILAB 650, Instrumentation Laboratory). The d-ROMs test (catalog code MC002) purchased from Diacron International (Grosseto, Italy) was used to measure reactive oxygen metabolites (ROM). Ferric-reducing antioxidant power (FRAP) was used to measure total antioxidant capacity using the colorimetric method of Benzie and Strain (1996). Activity of myeloperoxidase was measured via colorimetry based on the reaction of myeloperoxidase (MPO) contained in the plasma sample with hydrogen peroxide. Nitric oxide (NOx), nitrite, and nitrate concentrations were determined using the methods described by Trevisi et al. (2013). Retinol and tocopherol were extracted with hexane and analyzed by reverse- 
Table 1. Plasma biomarkers and PMN function from birth through $50 \mathrm{~d}$ of age in calves born to dams fed a basal control diet (CON) or the basal diet plus ethylcellulose rumen-protected methionine (MET) during the last $28 \mathrm{~d}$ of pregnancy ${ }^{1}$

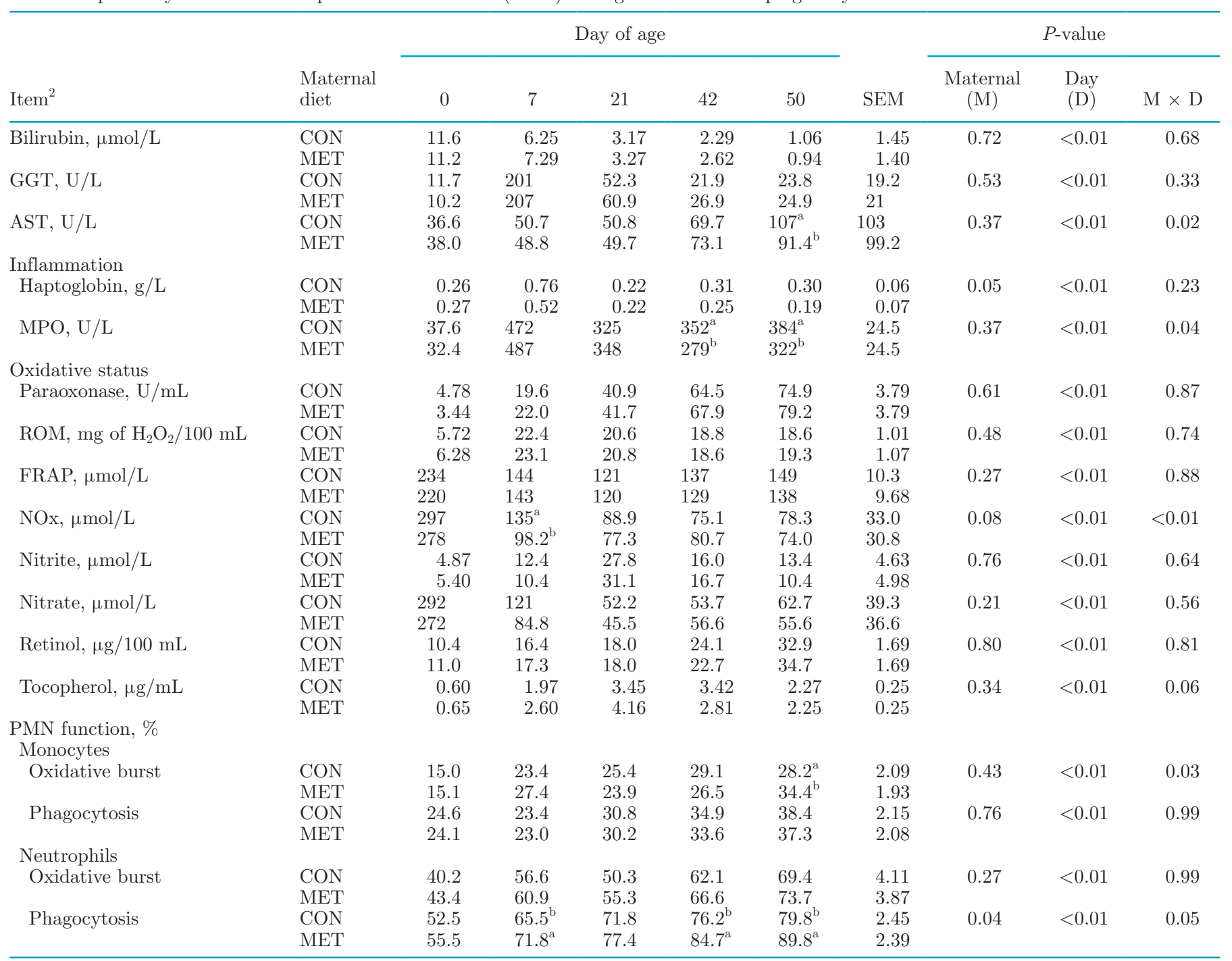

${ }^{\mathrm{a}, \mathrm{b}}$ Means within a column differ $(\mathrm{M} \times \mathrm{D} P<0.05)$. Longitudinal profiles for each group are depicted in Supplemental Figures S1 and S2 (https: //doi.org/10.3168/jds.2018-15676).

${ }^{1}$ MET diet consisted of Mepron at $0.09 \%$ of diet DM (Evonik Nutrition and Care GmbH, Hanau-Wolfgang, Germany). Calves were weaned after $42 \mathrm{~d}$ of age.

${ }^{2} \mathrm{GGT}=$ gamma-glutamyl transferase $; \mathrm{AST}=$ aspartate aminotransferase $; \mathrm{MPO}=$ myeloperoxidase $; \mathrm{ROM}=$ reactive oxygen metabolites; $\mathrm{FRAP}=$ ferric-reducing ability of plasma; $\mathrm{NOx}=$ nitric oxide.

phase HPLC using Spherisorb ODS-2, $3 \mu \mathrm{m}$, in a $150 \times$ $4.6 \mathrm{~mm}$ column (Alltech, Deerfield, IL); a UV detector set at 325 (for retinol) or $290 \mathrm{~nm}$ (for tocopherol); and 80:20 methanol:tetrahydrofuran as the mobile phase.

Neutrophils were isolated from blood collected in acid citrate dextrose (ACD)-containing evacuated tubes. Samples were centrifuged at $600 \times g$ for $30 \mathrm{~min}$ at $4^{\circ} \mathrm{C}$. Twenty-five milliliters of cold deionized water were added to lyse the red blood cells, followed by addition of $5 \mathrm{~mL}$ of $5 \times$ PBS. Samples were centrifuged at $200 \times$ $g$ for 10 min at $4^{\circ} \mathrm{C}$ and the supernatants decanted. Two subsequent washings using $10 \mathrm{~mL}$ of $1 \times \mathrm{PBS}$ at $4^{\circ} \mathrm{C}$ were performed, with samples centrifuged at $500 \times g$ for $5 \mathrm{~min}$ at $4^{\circ} \mathrm{C}$ and supernatants decanted. An aliquot $(20 \mu \mathrm{L})$ was used for PMN quantification and viability using a granulocyte primary antibody (CH138A, Veterinary Microbiology and Pathology, Washington State University, Pullman, WA), followed by a second antibody (Goat Anti-Mouse IgM, Human ads-PE, Southern Biotech, Birmingham, AL). Cells were fixed with 150 
$\mu \mathrm{L}$ of $4 \%$ paraformaldehyde (Sigma-Aldrich, St. Louis, $\mathrm{MO}$ ) and preserved at $4^{\circ} \mathrm{C}$ until flow cytometry reading (LSR II, Becton Dickinson, San Jose, CA).

Total RNA was extracted using the miRNeasy kit (Qiagen, Hilden, Germany) according to manufacturer's protocols. Samples were treated on-column with DNaseI (Qiagen). The RNA concentration was measured using a NanoDrop ND-1000 (NanoDrop Technologies, Rockland, DE), and RNA quality was measured using an Agilent 2100 Bioanalyzer (Agilent, Santa Clara, $\mathrm{CA}$ ). All samples used in the analysis were diluted with nuclease-free water to a concentration of $100 \mathrm{ng} \mathrm{RNA} /$ $\mu \mathrm{L}$ concentration. Quantitative PCR (qPCR) was performed using $4 \mu \mathrm{L}$ diluted cDNA combined with 6 $\mu \mathrm{L}$ of a mixture composed of $5 \mu \mathrm{L}$ SYBR Green master mix (Applied Biosystems, Waltham, MA), $0.4 \mu \mathrm{L}$ each of $10 \mu M$ forward and reverse primers, and 0.2 $\mu \mathrm{L}$ nuclease-free water, in a MicroAmp Optical 384Well Reaction Plate (Applied Biosystems). Additional details are reported in Supplemental Data (https://doi .org/10.3168/jds.2018-15676).

Phagocytosis capacity and oxidative burst activity of peripheral monocytes and neutrophils were determined simultaneously upon challenge with enteropathogenic bacteria (Escherichia coli 0118:H8). We incubated 200 $\mu \mathrm{L}$ of blood with $40 \mu \mathrm{L}$ of $100 \mu M$ dihydrorhodamine 123 (Sigma-Aldrich) and $40 \mu \mathrm{L}$ of propidium iodinelabeled bacteria $(109 \mathrm{cfu} / \mathrm{mL})$ at $38.5^{\circ} \mathrm{C}$ for $10 \mathrm{~min}$. After red blood cells were lysed with ice-cold MilliQ water (Millipore, Billerica, MA), cells were resuspended in PBS solution. Subsequently, monocytes were marked with APC anti-CD14 antibody (catalog number 301808; Biolegend, San Diego, CA), and neutrophils were stained with CH138A primary anti-bovine granulocyte monoclonal antibody (catalog number BOV2067, Washington State University) and PE-labeled secondary antibody (catalog number 1020-09S, Southern Biotech). The cells were re-suspended in PBS solution for flow cytometry analyses (LSR II; Becton Dickinson). Data are reported as percentages of CD14/CH138A-positive cells with phagocytosis and oxidative burst capability.

Data were analyzed using PROC MIXED of SAS (version 9.4; SAS Institute Inc., Cary, NC). Fixed effects in the model were maternal $\operatorname{diet}(\mathbf{M})$, day $(\mathbf{D})$, and their interactions $(\mathrm{M} \times \mathrm{D})$. Random effect was calf within M. The exponential correlation covariance structure SP (POW) for repeated measures was used for the analysis because time intervals were not evenly spaced. Data that were not normally distributed according to the Shapiro-Wilk test were log2-scale transformed. The transformed data were subjected to statistical analysis to determine treatment effects and were back-transformed for presentation purposes. Statistical differences were declared significant at $P<0.05$ and tendencies at $P<0.10$.

Compared with $\mathrm{CON}$ calves, the interaction $\mathrm{M} \times \mathrm{D}$ for $\operatorname{MPO}(P=0.04$; Table 1$)$ and $\operatorname{AST}(P=0.02)$ was due to MET calves having lower concentrations of MPO at 42 and $50 \mathrm{~d}$, and lower AST at $50 \mathrm{~d}$ (Supplemental Figure S1; https://doi.org/10.3168/jds.2018-15676). In addition, MET calves tended ( $\mathrm{M} P=0.08$ ) to have an overall lower concentration of NOx and haptoglobin ( $\mathrm{M} P=0.05)$ compared with CON calves. Nitric oxide concentration also had an $\mathrm{M} \times \mathrm{D}$ interaction, where at $7 \mathrm{~d}$ after birth MET calves had lower $(P<0.01$, Table 1) NOx concentrations compared with $\mathrm{CON}$ calves. A tendency $(P=0.06)$ for an $\mathrm{M} \times \mathrm{D}$ interaction in tocopherol concentration was detected, due to MET calves having greater concentrations at 7 and $21 \mathrm{~d}$ of age (Table 1), whereas at $42 \mathrm{~d}$ this trend changed in an opposite way $(\mathrm{CON}>\mathrm{MET}, P<0.01)$ due to a drastic decrease for MET calves between 21 and $42 \mathrm{~d}$ of age.

The lower concentrations of haptoglobin, NOx, and AST, coupled with lower MPO activity and greater concentrations of tocopherol in MET calves could be responses to adaptation to extrauterine life. In fact, the early period is particularly stressful, encompassing a rapid need to adapt to drastic physiologic changes (first $7 \mathrm{~d}$ of life) along with the gradual microbial colonization of the gut (21 to $50 \mathrm{~d}$ of age; Loor et al., 2002; Rey et al., 2014). The fact that MPO increased markedly at $7 \mathrm{~d}$ of age is suggestive of an activation of the oxidant status response (Jacometo et al., 2016). Given the lack of reference values for MPO in calves, it is difficult to establish with absolute confidence whether the values reported here denote oxidative stress. At least in nonruminants, changes in the level and activity of MPO in the circulation are associated with inflammation and oxidative stress (Ndrepepa, 2019).

In vitro neutrophil phagocytosis and oxidative burst were greater overall (M $P<0.05$; Table 1 ) in stimulated blood from MET calves compared with CON. In addition, neutrophil phagocytosis had an $\mathrm{M} \times \mathrm{D}$ interaction $(P<0.05$; Table 1$)$ for MET, compared with $\mathrm{CON}$ calves having greater neutrophil phagocytosis starting from d 7 through 50 d of age (Supplemental Figure S2; https://doi.org/10.3168/jds.2018-15676). The phagocytosis response, along with temporal increase in MPO concentration, could be interpreted as an indicator of a better innate immune responsiveness to an infectious challenge. By phagocytizing, killing, and digesting invading pathogens, neutrophils and macrophages represent the first line of defense of the innate immune system (Goff and Horst, 1997).

The mRNA abundance of TLR2 tended to be greater (M $P=0.07$; Table 2) in MET calves, and this group 
Table 2. Messenger RNA abundance in PMN from birth to $50 \mathrm{~d}$ of age in calves born to dams fed a basal control diet (CON) or the basal diet plus ethylcellulose rumen-protected methionine (MET) during the last $28 \mathrm{~d}$ of pregnancy ${ }^{1}$

\begin{tabular}{|c|c|c|c|c|c|c|c|c|c|c|}
\hline \multirow[b]{2}{*}{ Gene $^{2}$} & \multirow[b]{2}{*}{$\begin{array}{l}\text { Maternal } \\
\text { diet }\end{array}$} & \multicolumn{5}{|c|}{ Day of age } & \multirow[b]{2}{*}{ SEM } & \multicolumn{3}{|c|}{$P$-value } \\
\hline & & 0 & 7 & 21 & 42 & 50 & & $\begin{array}{l}\text { Maternal } \\
\text { (M) }\end{array}$ & $\begin{array}{l}\text { Day } \\
\text { (D) }\end{array}$ & $\mathrm{M} \times \mathrm{D}$ \\
\hline$T L R 2$ & MET & 2.43 & 1.91 & 0.73 & 1.25 & 1.69 & 0.66 & & & \\
\hline \multirow[t]{2}{*}{$T L R_{4}$} & $\mathrm{CON}$ & 2.33 & 1.38 & 1.06 & 1.29 & 0.87 & 0.68 & 0.37 & $<0.01$ & 0.55 \\
\hline & MET & 2.63 & 2.37 & 0.81 & 1.38 & 1.55 & 0.77 & & & \\
\hline \multirow[t]{2}{*}{ IL10 } & $\mathrm{CON}$ & 2.36 & 0.55 & 0.42 & 0.56 & 0.54 & 0.50 & 0.59 & $<0.01$ & 0.56 \\
\hline & MET & 1.81 & 0.71 & 0.32 & 0.50 & 0.45 & 0.38 & & & \\
\hline \multirow[t]{2}{*}{$I L 1 B$} & $\mathrm{CON}$ & 0.78 & 1.06 & 0.76 & 1.37 & 1.05 & 0.30 & 0.22 & $<0.01$ & 0.39 \\
\hline & MET & 0.68 & 1.77 & 0.78 & 1.53 & 1.78 & 0.39 & & & \\
\hline \multirow{2}{*}{$S 100 A 8$} & $\mathrm{CON}$ & 1.93 & 0.66 & 0.37 & 0.62 & 0.52 & 0.48 & 0.03 & $<0.01$ & 0.70 \\
\hline & MET & 2.83 & 1.47 & 0.46 & 0.83 & 0.93 & 0.65 & & & \\
\hline STAT3 & $\mathrm{CON}$ & 2.04 & $0.88^{\mathrm{b}}$ & 0.69 & 1.00 & 0.93 & 0.34 & 0.01 & $<0.01$ & $<0.01$ \\
\hline \multirow[t]{2}{*}{$D D X 58$} & $\mathrm{CON}$ & 0.51 & 1.70 & 0.61 & 1.27 & 1.17 & 0.49 & 0.39 & $<0.01$ & 0.84 \\
\hline & MET & 0.69 & 1.52 & 1.03 & 1.39 & 1.27 & 0.46 & & & \\
\hline \multirow[t]{2}{*}{ SOD1 } & $\mathrm{CON}$ & 0.86 & 0.93 & 1.25 & 1.46 & 1.31 & 0.21 & 0.07 & $<0.01$ & 0.95 \\
\hline & MET & 0.64 & 0.79 & 1.11 & 1.13 & 1.18 & 0.17 & & & \\
\hline \multirow[t]{2}{*}{ SOD2 } & $\mathrm{CON}$ & 1.15 & 1.18 & 0.56 & 0.90 & 0.67 & 0.37 & 0.18 & $<0.01$ & 0.77 \\
\hline & MET & 1.49 & 2.20 & 0.68 & 1.29 & 1.43 & 0.72 & & & \\
\hline \multirow[t]{2}{*}{$M P O$} & $\mathrm{CON}$ & 0.52 & 0.35 & 0.62 & 1.61 & 0.79 & 0.47 & 0.15 & $<0.01$ & 0.10 \\
\hline & MET & 0.75 & 0.58 & 0.41 & 1.91 & 2.36 & 0.69 & & & \\
\hline \multirow[t]{2}{*}{$N O X 1$} & $\mathrm{CON}$ & 0.50 & 0.41 & 0.62 & 2.45 & 2.60 & 0.84 & 0.27 & $<0.01$ & 0.54 \\
\hline & MET & 0.27 & 0.41 & 0.70 & 1.14 & 1.88 & 0.65 & & & \\
\hline \multirow[t]{2}{*}{ NOS2 } & $\mathrm{CON}$ & 3.09 & 0.28 & 0.53 & 1.69 & 0.84 & 1.12 & 0.96 & $<0.01$ & 0.19 \\
\hline & MET & 1.31 & 0.32 & 0.36 & 2.39 & 1.88 & 0.86 & & & \\
\hline \multirow[t]{2}{*}{$S L C 2 A 1$} & $\mathrm{CON}$ & 2.95 & $1.81^{\mathrm{a}}$ & $2.03^{\mathrm{b}}$ & 2.61 & 2.48 & 0.39 & 0.57 & $<0.01$ & 0.04 \\
\hline & MET & 2.78 & $1.25^{\mathrm{b}}$ & $2.89^{\mathrm{a}}$ & 2.62 & 3.32 & 0.46 & & & \\
\hline
\end{tabular}

${ }^{\mathrm{a}, \mathrm{b}}$ Means within a column differ $(\mathrm{M} \times \mathrm{D} P<0.05)$. Longitudinal profiles for each group are depicted in Supplemental Figure S3 (https://doi .org/10.3168/jds.2018-15676).

${ }^{1}$ MET diet consisted of Mepron at $0.09 \%$ of diet DM (Evonik Nutrition and Care GmbH, Hanau-Wolfgang, Germany). Calves were weaned after $42 \mathrm{~d}$ of age.

${ }^{2} T L R 2=$ toll-like receptor $2 ; T L R 4=$ toll-like receptor $4 ; N F K B 1=$ nuclear factor kappa B subunit $1 ; I L 10=$ interleukin $10 ; I L 1 B=$ interleukin $1-\beta ; S 100 A 8=$ S100 calcium binding protein A8; STAT3 = signal transducer and activator of transcription 3; TNF = tumor necrosis factor; $R X R A=$ retinoic-X-receptor $\alpha ; D D X 58=\mathrm{DExD} / \mathrm{H}$-box helicase $58 ; S O D 1=$ superoxide dismutase $1 ; S O D 2=$ superoxide dismutase $2 ; M P O$ $=$ myeloperoxidase; $N O X 1=\mathrm{NADPH}$ oxidase $1 ; N O S 2=$ nitric oxide synthase $2 ; S L C 2 A 1=$ solute carrier family 2 member $1 ; L D H A=$ lactate dehydrogenase A; $G S R=$ glutathione-disulfide reductase; $G S S=$ glutathione synthetase; $G P X 1=$ glutathione peroxidase 1.

showed a greater abundance of STAT3 (M $P=0.01$ Table 2) and $S 100 A 8$ (M $P=0.03$; Table 2; most evident in the first week of life) compared with CON calves. We found no significant interactions (Supplemental Figure S3; https://doi.org/10.3168/jds.2018-15676). Activation of TLR can induce a pro-inflammatory response, including synthesis of proteins that compose extracel- lular traps, such as S100A8 (Lee and Hwang, 2006; Moyes et al., 2010).

It is noteworthy that MET calves tended ( $\mathrm{M} P=$ $0.07)$ to have greater expression of GPX1. At least in non-ruminants, the maturation of phagocytic cells into monocytes and granulocytes upon a challenge is associated with an increase in GPX1 mRNA abundance 
(Shen et al., 1994), suggesting that transcription and production of GPX represent a way to protect PMN from toxic oxygen radicals and to enhance the elimination of as many pathogens as possible before dying from these same destructive products. Because in some human diseases, overexpression of GPX1 and other antioxidant defense enzymes is considered a good health prognosis (Tome et al., 2005), upregulation of GPX1 in MET calves also could be considered beneficial against oxidative status.

Calves in the MET group had an overall upregulation (M $P=0.05$ ) of $L D H A$ primarily during the first $7 \mathrm{~d}$ of life. In non-ruminant leukocytes, the protein encoded by this gene is primarily involved in the interconversion of pyruvate to lactate during glycolysis (Ganapathy et al., 2009). Activation of the inflammatory cascade in rats enhanced glucose uptake, pentose phosphate pathway activity, and lactate output from peritoneal leukocytes (Haji-Michael et al., 1999). Thus, lactate is considered an indicator of glucose metabolism by leukocytes, primarily via the pentose phosphate pathway, which generates reducing equivalents to support phagocytosis (Moyes, 2015). The upregulation of LDHA in MET calves during the first $7 \mathrm{~d}$ of life suggested a greater capacity for the conversion of pyruvate to lactate, but it cannot be discerned whether the rate of glucose utilization in PMN was affected.

Although absence of data on passive transfer of immunoglobulins is a limitation in the present study, overall, the data underscore the potential for maternal supply of Met during the last $30 \mathrm{~d}$ prepartum to enhance the ability of circulating innate immune cells of the calf to respond to a pathogen challenge in early life. The underlying mechanisms may include alterations in mRNA abundance (Loor et al., 2013). However, the existence of other molecular (e.g., epigenetic) or physiologic (e.g., glucose or nutrient uptake) mechanisms induced by the greater maternal supply of Met could not be discerned and should be studied in the future.

\section{ACKNOWLEDGMENTS}

A. S. Alharthi received a fellowship from King Saud University Riyadh, Saudi Arabia, to perform his $\mathrm{PhD}$ studies at the University of Illinois (Urbana). M. K. Abdelmegeid was supported by a postdoctoral fellowship from the government of the Arab Republic of Egypt. H. Dai was supported by a fellowship from China Scholarship Council (Beijing) to train at the University of Illinois (Urbana). F. Batistel was supported by a fellowship from Coordenação de Aperfeiçoamento de Pessoal de Nível Superior (CAPES, Brazilian Ministry of Education, Brasília, Brazil) and by Hatch funds un- der project ILLU-538-914, National Institute of Food and Agriculture (Washington, DC). The authors extend their appreciation to the Deanship of Scientific Research at King Saud University for funding this work through research group NO (RG-1436-021).

\section{REFERENCES}

Abdelmegeid, M. K., M. Vailati-Riboni, A. Alharthi, F. Batistel, and J. J. Loor. 2017. Supplemental methionine, choline, or taurine alter in vitro gene network expression of polymorphonuclear leukocytes from neonatal Holstein calves. J. Dairy Sci. 100:3155-3165. https://doi.org/10.3168/jds.2016-12025.

Batistel, F., J. M. Arroyo, A. Bellingeri, L. Wang, B. Saremi, C. Parys, E. Trevisi, F. C. Cardoso, and J. J. Loor. 2017. Ethyl-cellulose rumen-protected methionine enhances performance during the periparturient period and early lactation in Holstein dairy cows. J. Dairy Sci. 100:7455-7467. https://doi.org/10.3168/jds.2017-12689.

Batistel, F., J. M. Arroyo, C. I. M. Garces, E. Trevisi, C. Parys, M. A. Ballou, F. C. Cardoso, and J. J. Loor. 2018. Ethyl-cellulose rumen-protected methionine alleviates inflammation and oxidative stress and improves neutrophil function during the periparturient period and early lactation in Holstein dairy cows. J. Dairy Sci. 101:480-490. https://doi.org/10.3168/jds.2017-13185.

Benzie, I. F., and J. J. Strain. 1996. The ferric reducing ability of plasma (FRAP) as a measure of "antioxidant power": The FRAP assay. Anal. Biochem. 239:70-76. https://doi.org/10.1006/abio .1996 .0292 .

Blum, J. W. 2006. Nutritional physiology of neonatal calves. J. Anim. Physiol. Anim. Nutr. (Berl.) 90:1-11. https://doi.org/10.1111/j .1439-0396.2005.00614.x.

Chase, C. C., D. J. Hurley, and A. J. Reber. 2008. Neonatal immune development in the calf and its impact on vaccine response. Vet. Clin. North Am. Food Anim. Pract. 24:87-104. https://doi.org/10 .1016/j.cvfa.2007.11.001.

Du, X., T. Shen, H. Wang, X. Qin, D. Xing, Q. Ye, Z. Shi, Z. Fang, Y. Zhu, Y. Yang, Z. Peng, C. Zhao, B. Lv, X. Li, G. Liu, and X. Li. 2018. Adaptations of hepatic lipid metabolism and mitochondria in dairy cows with mild fatty liver. J. Dairy Sci. 101:9544-9558.

Futosi, K., S. Fodor, and A. Mocsai. 2013. Neutrophil cell surface receptors and their intracellular signal transduction pathways. Int. Immunopharmacol. 17:638-650. https://doi.org/10.1016/j.intimp .2013.06.034.

Ganapathy, V., M. Thangaraju, and P. D. Prasad. 2009. Nutrient transporters in cancer: Relevance to Warburg hypothesis and beyond. Pharmacol. Ther. 121:29-40. https://doi.org/10.1016/j .pharmthera.2008.09.005.

Goff, J. P., and R. L. Horst. 1997. Physiological changes at parturition and their relationship to metabolic disorders. J. Dairy Sci 80:1260-1268. https://doi.org/10.3168/jds.S0022-0302(97)76055 $-7$.

Haji-Michael, P. G., L. Ladriere, A. Sener, J. L. Vincent, and W. J. Malaisse. 1999. Leukocyte glycolysis and lactate output in animal sepsis and ex vivo human blood. Metabolism 48:779-785.

Jacometo, C. B., Z. Zhou, D. Luchini, E. Trevisi, M. N. Correa, and J. J. Loor. 2016. Maternal rumen-protected methionine supplementation and its effect on blood and liver biomarkers of energy metabolism, inflammation, and oxidative stress in neonatal Holstein calves. J. Dairy Sci. 99:6753-6763. https://doi.org/10.3168/ jds.2016-11018.

Kampen, A. H., I. Olsen, T. Tollersrud, A. K. Storset, and A. Lund. 2006. Lymphocyte subpopulations and neutrophil function in calves during the first 6 months of life. Vet. Immunol. Immunopathol. 113:53-63. https://doi.org/10.1016/j.vetimm.2006.04.001.

Kobayashi, S. D., and F. R. DeLeo. 2009. Role of neutrophils in innate immunity: A systems biology-level approach. Wiley Interdiscip. Rev. Syst. Biol. Med. 1:309-333. https://doi.org/10.1002/wsbm .32 . 
Lee, J. Y., and D. H. Hwang. 2006. The modulation of inflammatory gene expression by lipids: Mediation through Toll-like receptors. Mol. Cells 21:174-185.

Li, X., W. Huang, J. Gu, X. Du, L. Lei, X. Yuan, G. Sun, Z. Wang, X. Li, and G. Liu. 2015. SREBP-1c overactivates ROS-mediated hepatic NF-kB inflammatory pathway in dairy cows with fatty liver. Cell. Signal. 27:2099-2109.

Loor, J. J., A. B. Bandara, and J. H. Herbein. 2002. Characterization of 18:1 and 18:2 isomers produced during microbial biohydrogenation of unsaturated fatty acids from canola and soya bean oil in the rumen of lactating cows. J. Anim. Physiol. Anim. Nutr. (Berl.) 861:422-432

Loor, J. J., M. Bionaz, and J. K. Drackley. 2013. Systems physiology in dairy cattle: Nutritional genomics and beyond. Annu. Rev. Anim. Biosci. 1:365-392. https://doi.org/10.1146/annurev-animal $-031412-103728$.

McGuirk, S. M., and M. Collins. 2004. Managing the production, storage, and delivery of colostrum. Vet. Clin. North Am. Food Anim. Pract. 20:593-603. https://doi.org/10.1016/j.cvfa.2004.06.005.

Moyes, K. M., J. K. Drackley, D. E. Morin, and J. J. Loor. 2010. Greater expression of TLR2, TLR4, and IL6 due to negative energy balance is associated with lower expression of HLA-DRA and HLA-A in bovine blood neutrophils after intramammary mastitis challenge with Streptococcus uberis. Funct. Integr. Genomics 10:53-61. https://doi.org/10.1007/s10142-009-0154-7.

Moyes, K. M. 2015. Triennial Lactation Symposium: Nutrient partitioning during intramammary inflammation: A key to severity of mastitis and risk of subsequent diseases? J. Anim. Sci. 93:55865593. https://doi.org/10.2527/jas.2015-8945.

Ndrepepa, G. 2019. Myeloperoxidase - A bridge linking inflammation and oxidative stress with cardiovascular disease. Clin. Chim. Acta 493:36-51. https://doi.org/10.1016/j.cca.2019.02.022.

Osorio, J. S., P. Ji, J. K. Drackley, D. Luchini, and J. J. Loor. 2013a. Supplemental Smartamine M or MetaSmart during the transition period benefits postpartal cow performance and blood neutrophil function. J. Dairy Sci. 96:6248-6263. https://doi.org/10.3168/jds .2012-5790.

Osorio, J. S., E. Trevisi, M. A. Ballou, G. Bertoni, J. K. Drackley, and J. J. Loor. 2013b. Effect of the level of maternal energy intake prepartum on immunometabolic markers, polymorphonuclear leukocyte function, and neutrophil gene network expression in neonatal Holstein heifer calves. J. Dairy Sci. 96:3573-3587. https://doi.org/ $10.3168 /$ jds.2012-5759.

Osorio, J. S., E. Trevisi, P. Ji, J. K. Drackley, D. Luchini, G. Bertoni, and J. J. Loor. 2014. Biomarkers of inflammation, metabolism, and oxidative stress in blood, liver, and milk reveal a better immunometabolic status in peripartal cows supplemented with Smartamine M or MetaSmart. J. Dairy Sci. 97:7437-7450. https://doi .org/10.3168/jds.2013-7679.

Ranade, R., S. Talukder, G. Muscatello, and P. Celi. 2014. Assessment of oxidative stress biomarkers in exhaled breath condensate and blood of dairy heifer calves from birth to weaning. Vet. J. 202:583-587. https://doi.org/10.1016/j.tvjl.2014.10.025.

Rey, M., F. Enjalbert, S. Combes, L. Cauquil, O. Bouchez, and V. Monteils. 2014. Establishment of ruminal bacterial community in dairy calves from birth to weaning is sequential. J. Appl. Microbiol. 116:245-257. https://doi.org/10.1111/jam.12405.

Shen, Q., S. Chada, C. Whitney, and P. E. Newburger. 1994. Regulation of the human cellular glutathione peroxidase gene during in vitro myeloid and monocytic differentiation. Blood 84:3902-3908.

Tome, M. E., D. B. Johnson, L. M. Rimsza, R. A. Roberts, T. M. Grogan, T. P. Miller, L. W. Oberley, and M. M. Briehl. 2005. A redox signature score identifies diffuse large B-cell lymphoma patients with a poor prognosis. Blood 106:3594-3601. https://doi.org/10 .1182/blood-2005-02-0487.

Trevisi, E., G. Bertoni, R. Lombardelli, and A. Minuti. 2013. Relation of inflammation and liver function with the plasma cortisol response to adrenocorticotropin in early lactating dairy cows. J. Dairy Sci. 96:5712-5722. https://doi.org/10.3168/jds.2012-6375.

Xu, T., A. Alharthi, F. Batistel, A. Helmbrecht, C. Parys, E. Trevisi, X. Shen, and J. Loor. 2018. Hepatic phosphorylation status of serine/threonine kinase 1, mammalian target of rapamycin signaling proteins, and growth rate in Holstein heifer calves in response to maternal supply of methionine. J. Dairy Sci. 101:8476-8491. https: //doi.org/10.168/jds.2018-14378.

Zhou, Z., M. Vailati-Riboni, D. N. Luchini, and J. J. Loor. 2017. Methionine and choline supply during the periparturient period alter plasma amino acid and one-carbon metabolism profiles to various extents: Potential role in hepatic metabolism and antioxidant status. Nutrients 9:E10. https://doi.org/10.3390/nu9010010.

Zhou, Z., M. Vailati-Riboni, E. Trevisi, J. K. Drackley, D. N. Luchini, and J. J. Loor. 2016. Better postpartal performance in dairy cows supplemented with rumen-protected methionine compared with choline during the peripartal period. J. Dairy Sci. 99:8716-8732. https://doi.org/10.3168/jds.2015-10525.

Zhu, Y., G. Liu, X. Du, Z. Shi, M. Yin, X. Sha, X. Li, Z. Wang, and X. Li. 2019. Expression patterns of hepatic genes involved in lipid metabolism in cows with subclinical or clinical ketosis. J. Dairy Sci. 102:1725-1735. 